\title{
Isolated Inflammatory Arthritis of the Atlantooccipital Joint Confused with Migraine
}

DUŠKO KOZIĆ, PhD, Associate Professor, Oncology Institute of Vojvodina, Diagnostic Imaging Center, Sremska Kamenica; and University of Novi Sad, School of Medicine, Novi Sad, Serbia; MLADEN BJELAN, MD; VESNA NJAGULJ, MD, Oncology Institute of Vojvodina, Diagnostic Imaging Center, Sremska Kamenica, Serbia; MILOŠ LUČIĆ, PhD, Associate Professor, Oncology Institute of Vojvodina, Diagnostic Imaging Center, Sremska Kamenica, and University of Novi Sad, School of Medicine; MARIJA SEMNIC, PhD, Assistant Professor, Institute of Neurology, Clinical Center of Vojvodina, Novi Sad; and University of Novi Sad, School of Medicine; SNEŽANA CUPARA, PhD, Assistant Professor, University of Kragujevac, Faculty of Medical Sciences, Kragujevac, Serbia. Supported by the Ministry of Science and Technological Development, Belgrade, Serbia, Project number 175022. Address correspondence to Dr. Kozić, University of Novi Sad, School of Medicine, Institute of Oncology, Diagnostic Imaging Center, Put Dr. Goldmana 4, 21204 Sremska Kamenica, Serbia. E-mail: dusko.b.kozic@gmail.com. J Rheumatol 2013;40:2097-8; doi:10.3899/jrheum.121374

Magnetic resonance imaging (MRI) was performed in a 52-year-old woman with a several-year history of pharmacologically resistant, migraine-like, left hemicranial
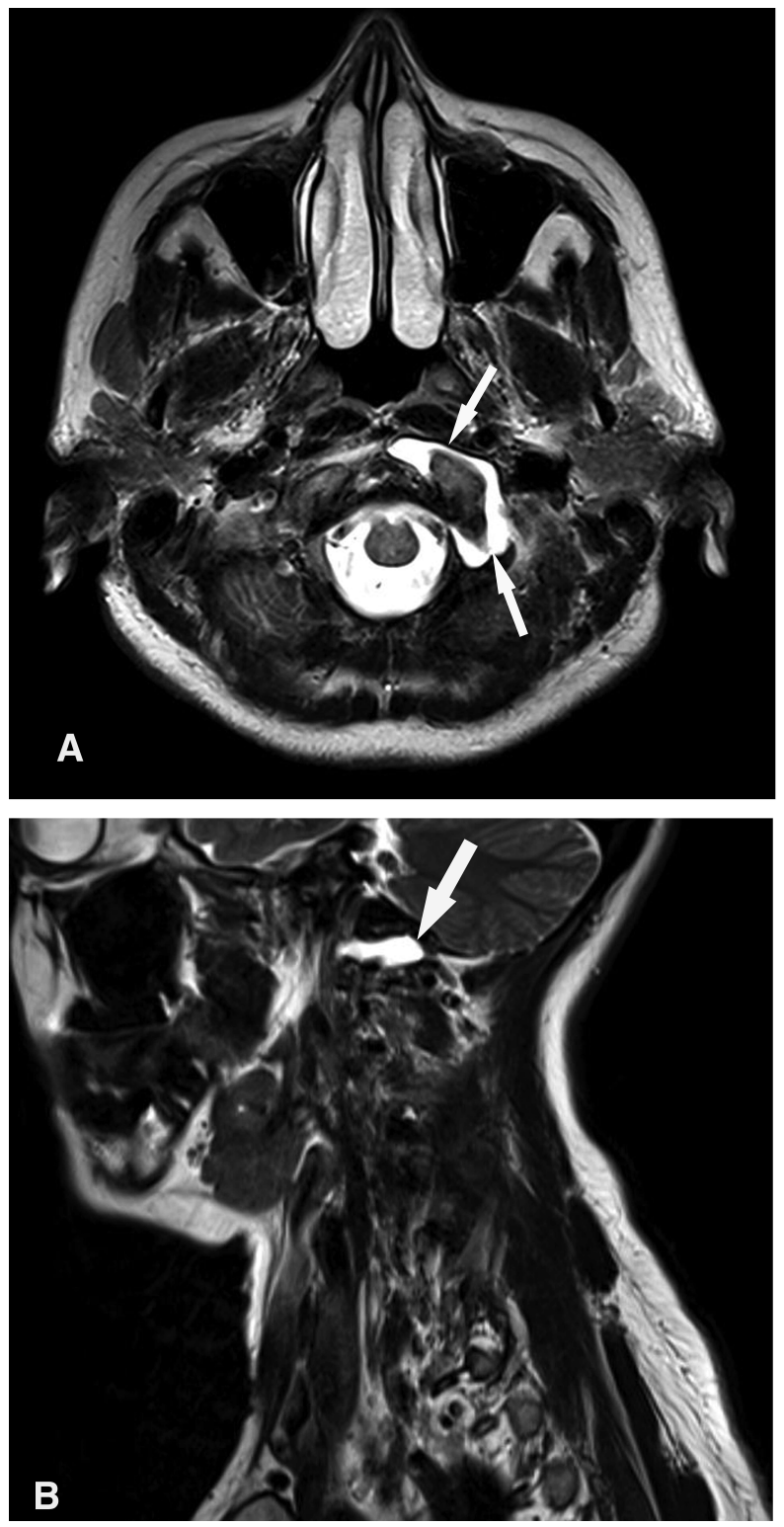

pain, lasting 48-72 h, accompanied with left eye "tunnel vision". The presence of synovial effusion (Figure 1A and 1B) and associated dilated vein without erosions of the joint

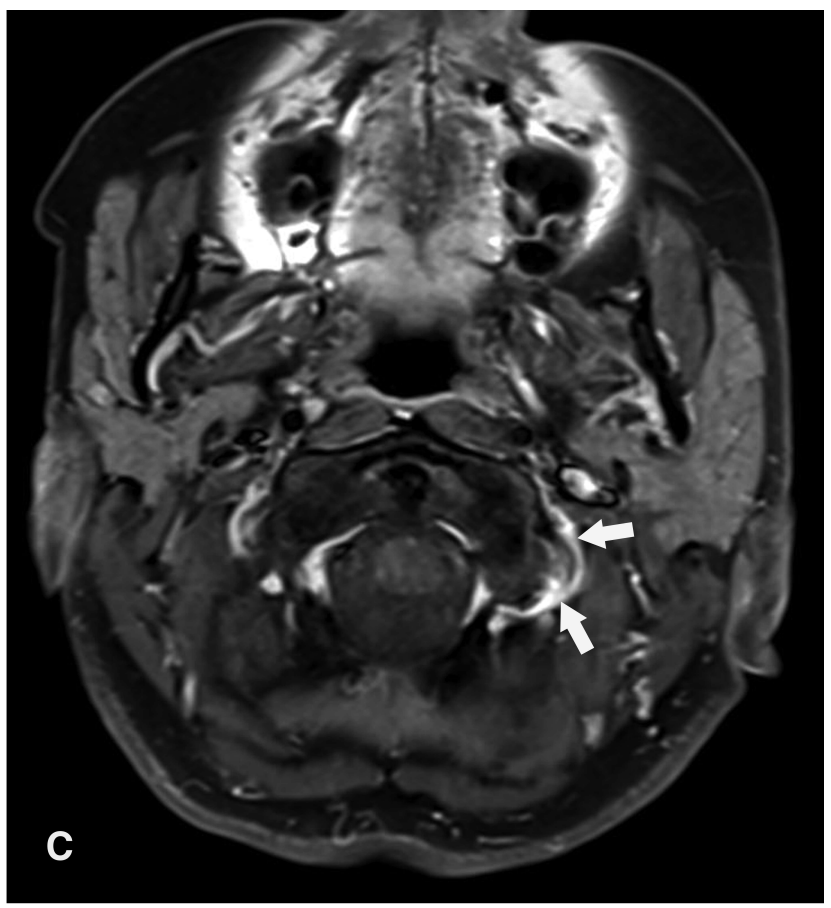

Figure 1. Magnetic resonance images of the left atlantooccipital joint: T2W transverse (A) and sagittal (B) images show the presence of moderate synovial effusion (arrows), while $\mathrm{T} 1$ fat-saturation axial sequence (C) after intravenous contrast administration shows the presence of the dilated vein associated with synovitis, without erosions of joint facets (short arrows).

Personal non-commercial use only. The Journal of Rheumatology Copyright @ C 2013. All rights reserved. 
facets and cartilage (Figure 1C) were revealed on precontrast and postcontrast MRI, consistent with inflammatory arthritis (IA). MRI of the brain and sacroiliac joints revealed no abnormalities.

No involvement of other joints was present. Rheumatoid factor (RF) was significantly positive, $>80 \mathrm{IU} / \mathrm{ml}$ (normal range 0-20 $\mathrm{IU} / \mathrm{ml}$ ), associated with markedly elevated erythrocyte sedimentation rate (ESR) and mildly elevated C-reactive protein levels.

After the antirheumatic treatment was administered (etoricoxib $90 \mathrm{mg} / \mathrm{day}$ ), the ESR decreased from 80 to 20 $\mathrm{mm} / \mathrm{h}$, while RF decreased to $40 \mathrm{IU} / \mathrm{ml}$. Marked release of migraine-like symptoms was evident. The involvement of the cervical spine in IA usually affects the atlantoaxial joints. Involvement of the atlantooccipital joint is much less frequent. Computed tomography with multiplanar reconstruction can document cervical spine bone damage and alignment abnormalities. However, MRI became the preferred modality for detection of spinal cord compression and evaluation of neural elements ${ }^{1}$. It is the only imaging tool that has the ability to assess simultaneously all relevant structures in inflammatory joint disease, including the synovium, cartilage, bone, ligaments, tendons, tendon sheaths, and the presence or absence of synovial fluid ${ }^{2}$ More recently, dynamic MRI studies have been used with the patient in flexed and extended positions for cervical spine IA evaluation ${ }^{3}$.

\section{REFERENCES}

1. Narvaez JA, Narvaez J, Serallonga M, De Lama E, de Albert M, Mast R, et al. Cervical spine involvement in rheumatoid arthritis: correlation between neurological manifestations and magnetic resonance imaging findings. Rheumatology 2008;47:1814-9.

2. Quinn M. Lessons from magnetic resonance imaging studies in rheumatoid arthritis. J Rheumatol 2008;35:372-4.

3. Karhu JO, Parkkola RK, Koskinen SK. Evaluation of flexion/extension of the upper cervical spine in patients with rheumatoid arthritis: an MRI study with a dedicated positioning device compared to conventional radiographs. Acta Radiologica 2005;46:55-66. 